\title{
Multimedia and machine learning approaches for data analytics
}

Published online: 31 October 2020

(C) Springer Science+Business Media, LLC, part of Springer Nature 2020

Multimedia Tools and Applications gratefully acknowledges the editorial work of the scholars listed below on the special issue entitled "Multimedia and Machine Learning Approaches for Data Analytics" (SI 1129 T).

Of 102 papers submitted to this issue, 26 were eventually accepted after a stringent peer review process.

\section{Corresponding Guest Editor \\ Wankou Yang \\ Southeast University, Nanjing, China \\ Email: wkyang@seu.edu.cn}

\section{Guest Editor}

\section{Deepak Kumar Jain}

Chinese Academy of Sciences, Beijing, China

Email: dkj@ieee.org

Publisher's note Springer Nature remains neutral with regard to jurisdictional claims in published maps and institutional affiliations. 